World Journal of Environmental Biosciences

All Rights Reserved WJES (C) 2014

Available Online at: www.environmentaljournals.org

Volume 10, Issue 3: 31-37

https://doi.org/10.51847/Tb7RtCsagp

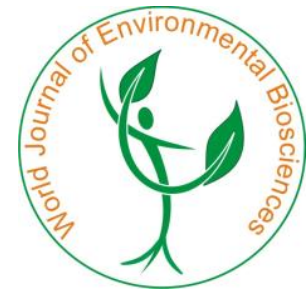

ISSN 2277- 8047

\title{
Comparison of the Immunogenicity of GTPV A27R, GTPV L1R, and SPPV A33R Recombinant Proteins
}

\author{
Takele Tesgera Hurisa ${ }^{1}$, Guohua Chen ${ }^{1}$, Huaijie Jia ${ }^{1}$, Fang Yong Xiang ${ }^{1}$, Xiao-Bing He ${ }^{1}$, \\ Zhi-Zhong Jing ${ }^{1 *}$
}
${ }^{1}$ State Key Laboratory of Veterinary Etiological Biology, Key Laboratory of Veterinary Public Health of Agriculture Ministry, Lanzhou Veterinary Research Institute, Chinese Academy of Agricultural Sciences, Lanzhou 730046, Gansu, China.

\begin{abstract}
The three poxviruses' namely lumpy skin disease, Goatpox, and Sheeppox viruses are categorized under the genera of Capripoxvirus based on their genome similarities. The disease caused by these viruses is complex and difficult to diagnose; the most important reasons for this are the visible variability in the host range, the clinical similarities, and the inability to differentiate by serological assays. By considering their antigenic and immunogenic similarities of capripoxviruses, this study aimed at the comparison of the immunogenicity of GTPV A27R, GTPV $L 1 R$, and SPPV A33R recombinant proteins. Concerning this study, $35 \mathrm{kDa}, 26 \mathrm{kDa}$, and $19 \mathrm{kDa}$ recombinant proteins were purified as regards GTPV A27R, GTPV L1R, and SPPV A33R respectively. The best antibody titer was revealed by GTPV A27R with the test sensitivity of $90 \%, 100$ $\%, 90 \%$, and diagnostic accuracy of $100 \%, 90 \%$, and $100 \%$ for sera of Cattle, Sheep, and Goat correspondingly. Based on the available results GTPV A27R protein showed more immunogenicity while compared with the rest of the two proteins and further studies are required in the same area for the future.
\end{abstract}

Keywords: Antibody, GTPV A27R, GTPV L1R, Immunogenicity, SPPV A33R, Rabbit

Corresponding author: Zhi-Zhong Jing

e-mail $\bowtie$ zhizhongj@163.com

Received: 20 June 2021

Accepted: 27 Septembr 2021

\section{INTRODUCTION}

One of the eight genera in the subfamily chordopoxvirinae (ChPV) and the family Poxviridae is Capripoxviruses (CaPVs). The genus Capripoxvirus consists of Lumpy skin disease virus (LSDV), Goatpox virus (GTPV), and Sheeppox virus (SPPV), which cause disease in Cattle, Goats, and Sheep, respectively. Domestic ruminants' most important economic disorders in Asia and Africa are driven by these viruses (Esposito \& Fenner, 2001; Tuppurainen et al., 2021). The ability to cause experimental or natural cross-infect and disease in GTPV and SPPV strains in both host species has already been described (Haegeman et al., 2021; Kenubih et al., 2021; Rouby et al., 2021). Due to the visible variability in the host range, the clinical resemblance, and the inability to diagnose the two diseases by serological assays, SPPV and GTPV belong to a group of infections caused by a single viral species. Host range characteristics are observable due to regional viral adaptations to goat or sheep hosts (He et al., 2020). LSDV, GTPV, and SPPV have a similar orthologous genes range; only GTPV and SPPV lack 9 LSDV genes with likely CaPV virulence and host range functions (Tulman et al., 2002).

Since these viruses are genetically related and cross-reactive, the immunogenic protein identified from one species of virus can detect antibodies produced against the other two capripoxviruses (Almoslim \& Ibrahim, 2020; Ibrahim et al.,
2020). The proteins used in this study were selected according to their immunogenic properties of the most studied representative of the Poxviridae family. According to studies, some VACV proteins induce certain cellular and humoral immune responses and protect against subsequent orthopoxvirus infections. Thus, the proteins encoded by A27L are the most appropriate candidate described for the development of subunit vaccines (Ramirez et al., 2002), D8L (Chervyakova et al., 2016), H3L (Lin et al., 2000; Davies et al., 2005), L1R (Kim et al., 2017; Shchelkunov et al., 2021), B5R (Law \& Smith, 2001; Melamed et al., 2018), A33R (Hooper et al., 2003; Fogg et al., 2007) genes. Regarding this study, we selected GTPV A27R, GTPV L1R, and SPPV A33R proteins and compared their immunogenicity after coating. During the process LSDV, inactivated virion of GTPV, and SPPV vaccines were prepared and rabbits were immunized subcutaneously at multiple sites and later boosted at an interval of 14 days three times, subsequently, the blood was collected at each step. After the candidate proteins were coated, an endpoint antibody titer was conducted, and using Microsoft excel window 10, the mean's OD values were analyzed.

\section{MATERIAL AND METHODS}

\section{Protein preparation}

The protein construction was carried out as an application and preparing a method of a group of Goatpox virus recombinant protein antigens patent application number 201811241377. GTPV A27R, GTPV L1R, and SPPV A33R genes were cloned to 
vector pET30a plasmid, the cloned vector was transformed to $E$. coli bacteria BL-21, and the protein was expressed. The transformed bacteria were allowed to grow at $37^{\circ} \mathrm{C}$ for $12 \mathrm{hrs}$ on an agar medium. Following bacterial growth, individual colonies were picked up by sterile tips and cultured to LB broth medium which was prepared from Tryptone, yeast extract, and Sodium chloride with kanamycin. Again, the culture was incubated at $37^{\circ} \mathrm{C}$ overnight with agitation ( $\left.200 \mathrm{rpm}\right)$. After the $\mathrm{OD}_{600}$ value was reached $0.6,0.1 \mathrm{mM}$ isopropyl- $\beta$-Dthiogalactopyranoside (IPTG) was added and incubated at $37^{\circ} \mathrm{C}$ until full bacterial growth was observed. Centrifuges were performed at $6000 \mathrm{rpm}$ for $10 \mathrm{~min}$. The sediments were collected and washed three times using PBS (Phosphate Buffered Saline) at $5000 \mathrm{rpm}$ for $30 \mathrm{~min}$. After washing, the sediment was suspended by $15 \mathrm{ml}$ PBS, freeze-thawed, and ultra-sonicated three cycles for $10 \mathrm{~min}$, and centrifuged at $10,000 \mathrm{rpm}$ for $20 \mathrm{~min}$. Again, the sediments were collected, washed with $2 \mathrm{M}$ buffer (urea), and centrifuged three times for $20 \mathrm{~min}$ before the sediments were collected. Subsequently, 8M urea was added and kept for $1 \mathrm{hr}$ at room temperature. After $1 \mathrm{hr}$ incubation, continued centrifugation at 10,000 rpm for $30 \mathrm{~min}$ and collected the supernatant. Affinity resin was prepared and mixed to the supernatant, agitated for $1 \mathrm{hr}$ at room temperature, and purified by affinity chromatography system using different concentrations of Imidazole $(20 \mathrm{M}, 50 \mathrm{M}, 100 \mathrm{M}, 200 \mathrm{M}, 300 \mathrm{M}$, and $400 \mathrm{M}$ ). A better protein elusion was observed by $200 \mathrm{M}$ Imidazole. The Purified protein analysis was performed by SDSPAGE with Page RulerTM Prestained Protein Ladder Parts No 26616, 26617 standard molecular protein markers. The eluted proteins were ultra-filtered at $3500 \times \mathrm{g}$ for $30 \mathrm{~min}$ in $+4^{\circ} \mathrm{C}$ using Amicon $^{\mathrm{R}}$ Ultra 15-10k Centrifugal filter device on a volume of $15 \mathrm{ml}$ and collected from the filter device. After ultrafiltration, dialysis was followed using different concentrations of urea $(2 \mathrm{M}, 4 \mathrm{M}$, and $6 \mathrm{M})$ at $+4^{\circ} \mathrm{C}$ which was later quantified by Coomassie (Bradford) protein assay kit.

\section{Antibody production and detection}

Genetically validated female New Zealand white rabbits ( $\mathrm{N}=12)$ were used to produce antibodies. The Rabbits were divided into LSDV, GTPV virion, and SPPV vaccines and control. In the trial group, $1 \mathrm{ml}$ of Neethling LSDV vaccine, which was cultured on Vero cells, $2 \mathrm{ml}$ of formalin-inactivated virion of GTPV strain AV41, and SPPV strain AV42 containing 0.5mg immunogen was emulsified with an equal volume of Freund's complete adjuvant and immunized subcutaneously (SC) at multiple sites and the control groups were immunized with normal saline without the virus. The rabbits were again injected three more times at 14 days intervals by the same concentration of the vaccines with Freund's incomplete adjuvant as a boost. The blood was gotten from a vein in the ear and allowed to clot for $3 \mathrm{hrs}$ at room temperature which was later centrifuged at 5,000 rpm for 10 $\min$ at $+4^{\circ} \mathrm{C}$. The supernatants were collected and stored at $20^{\circ} \mathrm{C}$ until used for titration of antibody.

Before every immunization and 2 weeks after the final injection, the blood was collected and using the enzyme-linked immunosorbent assay (I-ELISA) as demonstrated previously (Vogt et al., 2021), antibody titer of all serum samples was measured which was optimized in the laboratory. 96 well flatbottom microtiter plates (Nunc, Beckton-Dickinson, NJ) were coated with $0.5 \mu \mathrm{g} / \mathrm{ml}$ for each of the proteins in coating buffer
(100 $\mathrm{ll} /$ well) and incubated overnight for $14 \mathrm{hrs}$ at $+4{ }^{\circ} \mathrm{C}$ then washed three times by PBS containing $0.05 \%$ tween 20 (PBST). After washing, $200 \mu$ l of $1 \%$ BSA (Bovine Serum Albumin) fraction V (Roche, Germany) in PBS was added for bocking and incubated for $2 \mathrm{hrs}$ at $37^{\circ} \mathrm{C}$. The collected serum was diluted serially in each well and again incubated for $1 \mathrm{hr}$ at $37^{\circ} \mathrm{C}$. Following washing steps mouse anti-rabbit IgG conjugated with HRP was diluted in blocking buffer in the ratio of 1:8000 $(100 \mu \mathrm{l} /$ well $)$ and added to each well. After the incubation and washing process, $100 \mu \mathrm{l}$ of the substrate $(55 \mathrm{mM} \mathrm{3,} \mathrm{3',} \mathrm{5,} \mathrm{5'-}$ tetramethylbenzidine, $0.03 \% \mathrm{H} 202$ ) was added to each well and again incubated at $37^{\circ} \mathrm{C}$ for $15 \mathrm{~min}$. Following incubation, stopped the reaction by $50 \mu \mathrm{l}$ of $2 \mathrm{M} \mathrm{H}_{2} \mathrm{SO}_{4}$, and the OD value was read at $450 \mathrm{~nm}$ using the spectrophotometer (Alhajj \& Farhana, 2021). After each step of blood collection, antibody titration was performed separately as described above. No animals had clinical signs of immunization or died during the experiment, and all rabbits were sacrificed with cervical dislocation after anesthesia following final blood collection.

\section{Ethics statement}

Responsible government authorities (Office of Health and Social Affairs at the Lanzhou Veterinary Research Institute; license number SYK2015-0003) registered and approved the rabbits used during the experiment. The rabbits were kept following national regulations. The rabbit's physical conditions were observed daily and were kept under proper husbandry. During the activity of the experiment, no animal died or was ill at any time. Blood from the rabbit was collected safely. During the experimental period following established best practices, every endeavor was made to minimize distress and pain (Carstens \& Moberg, 2000).

\section{RESULTS AND DISCUSSION}

Immunogenic proteins of GTPV and SPPV were selected based on the information of their immunogenicity and antigenicity studied before. The produced recombinant proteins were purified and $35 \mathrm{kDa}, 26 \mathrm{kDa}$, and $19 \mathrm{kDa}$ bands were detected by SDS-PAGE for GTPV A27R, GTPV L1R, and SPPV A33R respectively. A non-specific protein band was observed regarding GTPV A27R during SDS-PAGE protein analysis. The protein concentration was estimated and the coating antigen was optimized as $0.5 \mu \mathrm{g} / \mathrm{ml}$ concerning three of the proteins. Besides, the antibodies produced against the LSDV, the whole virion of the GTPV and SPPV vaccines were titered in each step of blood collection. Microsoft Excel Window 10 performed the mean analysis of OD values of titrated antibodies. A better titer was observed by GTPV A27R antigen for antibodies produced against LSDV, Virion of GTPV, and SPPV vaccines. Regarding GTPV L1R protein, also a virtuous titer was observed for the antibodies produced against the LSDV and Virion of GTPV vaccines. A relatively less titer was predicted by SPPV A33R protein for antibodies produced against three of the vaccines (Figures 4-6). Overall, there was a variation of antibody titer within each protein involved in this experimental study which may indicate the distinction in immunogenicity of individual proteins and the ability of antibody conversion of each rabbit as indicated by graph lines. 
M.

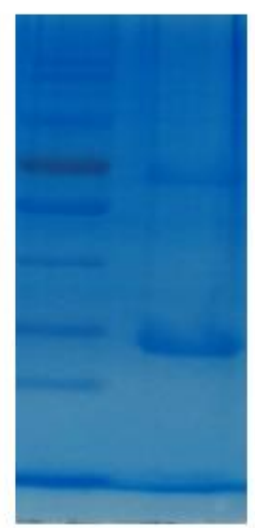

GTPV A27R; $35 \mathrm{kDa}$

Figure 1. Expressed and the purified fraction of a $35 \mathrm{kDa}$ recombinant GTPV A27R fusion protein by affinity chromatography and Lane M: Protein standard marker.

M

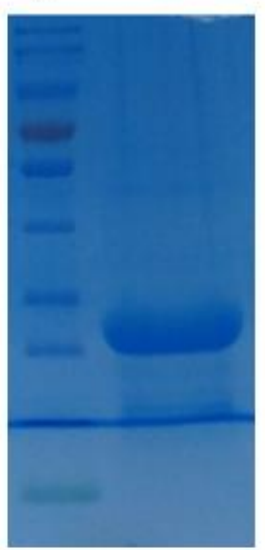

GTPV L1R; 26kDa

Figure 2. Expressed and purified fraction of a $26 \mathrm{kDa}$ recombinant GTPV L1R fusion protein by affinity chromatography and Lane M: Protein standard marker.

M

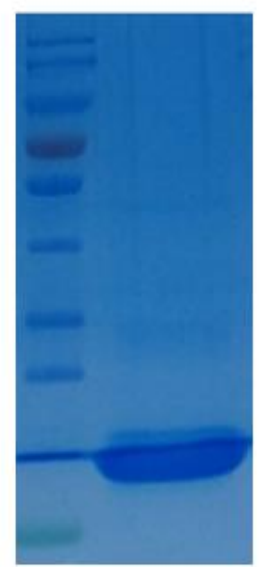

SPPV A33R; 19kDa

Figure 3. Expressed and purified fraction of a $19 \mathrm{kDa}$ recombinant SPPV A33R fusion protein by affinity chromatography and Lane M: Protein standard marker. 


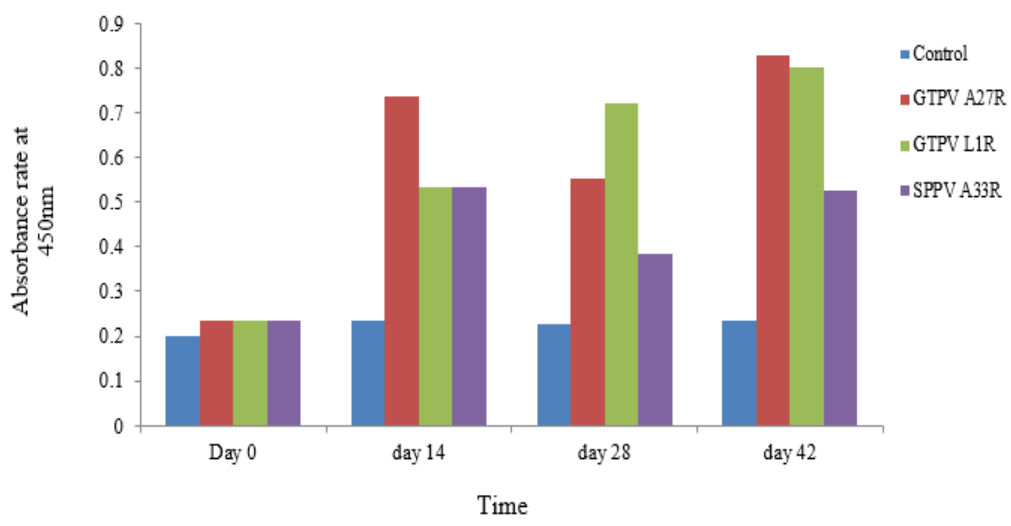

Figure 4. The detection ability of GTPV A27R, GTPV L1R, and SPPV A33R proteins was assessed using polyclonal antibodies produced following immunization of rabbits by Virion of GTPV vaccine and control. After the polyclonal antibodies were produced, the antibody detection ability of the three proteins was measured. A better titer was revealed by GTPV A27R and GTPV L1R after the second immunization and less detection ability was noticed by SPPV A33R protein. The antibody titer conducted by GTPV L1R protein was constantly elevated following immunization.

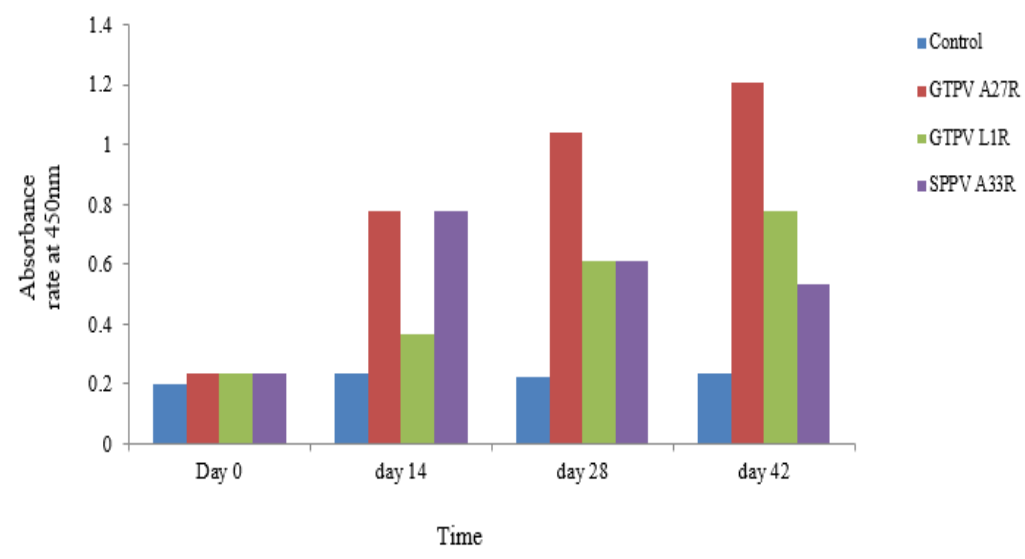

Figure 5. The detection ability of GTPV A27R, GTPV L1R, and SPPV A33R proteins was assessed using polyclonal antibodies produced after rabbits were immunized by the Virion of SPPV vaccine and control. A better antibody titer was revealed by GTPV A27R which showed elevation of antibody started after the second immunization. Less titer was detected regarding GTPV L1R and SPPV A33R protein.

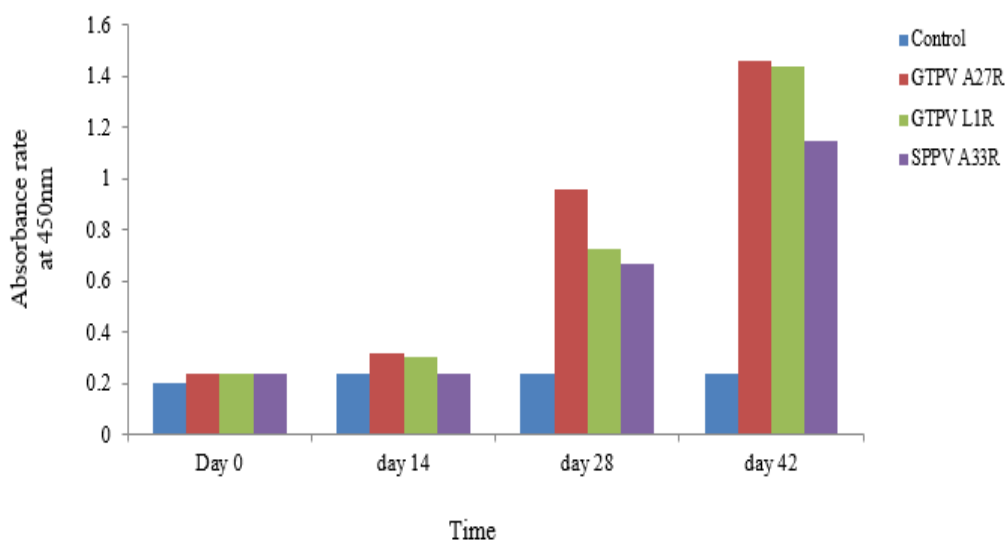

Figure 6. The detection ability of GTPV A27R, GTPV L1R, and SPPV A33R proteins using polyclonal antibodies produced after rabbits were immunized by LSDV vaccine and control. After the polyclonal antibodies were produced, the antibody titration ability of the three proteins was assessed. Elevation of antibodies was started after the third immunization. A better antibody titer was shown by GTPV A27R, GTPV L1R, and SPPV A33R proteins respectively. 
The test sensitivity and diagnostic accuracy

To evaluate test sensitivity preliminary estimates and diagnostic accuracy, naturally infected $(n=20)$ positive and negative serum of Cattle, Sheep, and Goat were used. The serum was tested using GTPV A27R, GTPV L1R, and SPPVA33R proteins by indirect ELISA method in two-fold dilutions ranging from 1:200 to 1:800. An ELISA cut-off value for serum tested at 1:400 dilution was determined for Cattle, Sheep, and Goat. Concerning GTPV A27R protein, the estimated sensitivity was $90 \%$ for the serum of Cattle and Goat and $100 \%$ for the serum of Sheep. The accuracy was $100 \%$ for Cattle and Goat but $90 \%$ for Sheep. Regarding GTPV L1R protein, the sensitivity was estimated as $90 \%$ for cattle and $100 \%$ for both Sheep and Goat. Whereas the diagnostic accuracy was $70 \%$ for Sheep and goats and $100 \%$ for Cattle. Similarly, while serum was tested by SPPV A33R, sensitivity was $100 \%$ for the serum of Cattle, Sheep, and Goat and the test accuracy was $70 \%$ for Cattle $80 \%$ for Sheep and Goat serum.

Capripoxviruses are antigenically very closely related (Hamdi et al., 2020). In the detection of SPPV antibodies, many antigenic proteins and their associated genes were used by immunosorbent assay in the blood sera of cattle, goats, and sheep (Teffera \& Babiuk, 2019). In this study, based on immunogenic properties, the proteins used were selected from the most important member of the Poxviridae family. Preservation of the L1R protein as part of the mature virion membrane occurs in all sequenced poxviruses (Gubser et al., 2004). An L1R-based vaccine has been reported to be developed against a poxvirus that stimulates the immunity of the entire poxviruses group's (Earl et al., 2004). However, according to reports from another study, D8 and A27R are suitable for inducing antibodies to detect superior L1R. The main reason for this is the general availability and abundance of epitopes on the surface of viral particles. In pure IMV particles, L1 is found at least ten times less, while D8 and A27 are very common surface proteins. In addition, both the D8 and A27 are presented in a multimodal form (Matho et al., 2012; Chang et al., 2013; Matho et al., 2014), which investigates the bivalent interaction of mAbs with the surface proteins makes it possible and connects with higher avidity.

So far, there are missing data about the individual SPPV protein's immunological properties and the neutralization of the activity of antibodies to these proteins. However, Olga V. Chervyakova et al., 2016, studied the immunogenic and antigenic properties of SPPV-060, SPPV-095, SPPV-117, and SPPV-122 proteins of SPPV, orthologs of VACV L1, A4, A27, and A33 proteins respectively (Chervyakova et al., 2016). In this trial, antibodies were produced after the rabbits were immunized with the LSDV, Virion of GTPV, and SPPV vaccines, and the immunogenicity of the three candidate proteins was evaluated. In the case of the antibody produced against the LSD vaccine, the antibody titer was elevated after the third immunization with better titration by GTPV A27R followed by GTPV L1R and SPPVA33R proteins. Similarly as regards rabbits injected with virion of the GTPV and SPPV vaccines also a significant magnitude was recognized for GTPV A 27R and GTPV L1R proteins. Less titer of antibodies was seen for rabbits immunized with GTPV vaccine by GTPV A27R which may be related to the antibody provoking ability of the vaccines. The test sensitivity and diagnostic accuracy of each of the proteins were described in the result section. Concerning this experimental work, SPPV A33R protein was observed as less antibody titer with better test sensitivity which may need further study. Also, a clear variation of antibody conversion ability of individual rabbits was detected within each protein used for titration, which may indicate the distinction in immunogenicity of individual proteins as indicated by graph lines. In conclusion, even though three of the proteins detected serum antibodies, a better antibody detection ability was noticed regarding the GTPV A27R protein.

\section{CONCLUSION}

In this preliminary study, the immunogenicity of three Capripoxvirus proteins was evaluated. GTPV A27R proteins were showed a better detection ability while compared with GTPV L1R, and SPPV A33R proteins and can be used for the detection of antibodies produced against Capripoxvirus.

\section{ACKNOWLEDGMENTS: None}

\section{CONFLICT OF INTEREST: None}

FINANCIAL SUPPORT: This work is supported by the 13th Five-year Plan National Science and Technology Support Program (Grant number 2017YFD0500903) State Key Laboratory of Veterinary Etiological Biology, Key Laboratory of Veterinary Public Health of Agriculture Ministry, Lanzhou Veterinary Research Institute, Chinese Academy of Agricultural Sciences. Funding bodies had no roles in the study's design and collection, analysis, and interpretation of data and in writing the manuscript.

ETHICS STATEMENT: We purchased animals from Lanzhou veterinary research institute's laboratory animal breeding section. All animal experiments followed the regulations of the Institutional Animal Care and Use Committee. The responsible governmental authorities Office for Health and Social Affairs registered and approved the animals at Lanzhou veterinary research institute Licence number SYK2015-0003.

\section{REFERENCES}

Alhajj, M., \& Farhana, A. (2021). Enzyme linked immunosorbent assay. StatPearls [Internet]. Bookshelf ID: NBK555922PMID:32310382.

Almoslim, H., \& Ibrahim, S. (2020). Anorexic: impact of complement protein along with additional food consumption and exercise on ectomorphism and energy variable amongst males. Pharmacophore, 11(4), 83-87.

Carstens, E., \& Moberg, G. P. (2000). Recognizing pain and distress in laboratory animals. Ilar Journal, 41(2), 62-71. PMID: 11304586.

Chang, T. H., Chang, S. J., Hsieh, F. L., Ko, T. P., Lin, C. T., Ho, M. R., Wang, I., Hsu, S. T. D., Guo, R. T., Chang, W., et al. (2013). Crystal structure of vaccinia viral A27 protein reveals a novel structure critical for its function and complex formation with A26 protein. PLoS Pathogens, 9(8), e1003563. doi:10.1371/journal.ppat.1003563.

Chervyakova, O. V., Zaitsev, V. L., Iskakov, B. K., Tailakova, E. T., Strochkov, V. M., Sultankulova, K. T., Sandybayev, N. T., 
Stanbekova, G. E., Beisenov, D. K., Abduraimov, Y. O., et al. (2016). Recombinant sheep pox virus proteins elicit neutralizing antibodies. Viruses, 8(6), 159. doi:10.3390/v8060159.

Davies, D. H., McCausland, M. M., Valdez, C., Huynh, D., Hernandez, J. E., Mu, Y., Hirst, S., Villarreal, L., Felgner, P. L., \& Crotty, S. (2005). Vaccinia virus H3L envelope protein is a major target of neutralizing antibodies in humans and elicits protection against lethal challenge in mice. Journal of virology, 79(18), 11724-11733.

Earl, P. L., Americo, J. L., Wyatt, L. S., Eller, L. A., Whitbeck, J. C., Cohen, G. H., Eisenberg, R. J., Hartmann, C. J., Jackson, D. L., Kulesh, D. A., et al. (2004). Immunogenicity of a highly attenuated MVA smallpox vaccine and protection against monkeypox. Nature, 428(6979), 182-185.

Esposito, J. J., \& Fenner, F. (2001). Poxviruses, p. 2885-2921. In B. N. Fields, D. M. Knipe, P. M. Howley, R. M. Chanock, J. L. Melnick, T. P. Monathy, B. Roizman, and S. E. Straus (ed.), Fields virology, 4th ed. Lippincott, Williams and Wilkins, Philadelphia, $P A$.

Fogg, C. N., Americo, J. L., Lustig, S., Huggins, J. W., Smith, S. K., Damon, I., Resch, W., Earl, P. L., Klinman, D. M., \& Moss, B. (2007). Adjuvant-enhanced antibody responses to recombinant proteins correlates with protection of mice and monkeys to orthopoxvirus challenges. Vaccine, 25(15), 2787-2799.

Gubser, C., Hue, S., Kellam, P., \& Smith, G. L. (2004). Poxvirus genomes: a phylogenetic analysis. Journal of General Virology, 85(1), 105-117.

Haegeman, A., De Leeuw, I., Saduakassova, M., Van Campe, W., Aerts, L., Philips, W., Sultanov, A., Mostin, L., \& De Clercq, K. (2021). The Importance of Quality Control of LSDV Live Attenuated Vaccines for Its Safe Application in the Field. Vaccines, 9(9), 1019. doi:10.3390/vaccines9091019.

Hamdi, J., Bamouh, Z., Jazouli, M., Boumart, Z., Tadlaoui, K. O., Fihri, O. F., \& Harrak, M. E. (2020). Experimental evaluation of the cross-protection between Sheeppox and bovine Lumpy skin vaccines. Scientific Reports, 10(1), 1-9. doi:10.1038/s41598-020-65856-7.

He, C., Tong, J., Zhang, X., Tuohetiniyazi, M., Zhang, Y., \& Li, Y. (2020). Comparative analysis of ankyrin (ANK) genes of five capripoxviruses isolate strains from Xinjiang province in China. Virology Journal, 17(1),133. doi:10.1186/s12985-020-01407-w.

Hooper, J. W., Custer, D. M., \& Thompson, E. (2003). Four-genecombination DNA vaccine protects mice against a lethal vaccinia virus challenge and elicits appropriate antibody responses in nonhuman primates. Virology, 306(1), 181195.

Ibrahim, S., Al-Ameer, A., Abu-Hilal, H., Allen, J., \& Watkins, P. (2020). Effect of Protein Supplementation plus HyperCaloric intake and Exercise on Hypertrophy, Hormones and Energy components among Underweight Males. International Journal of Pharmaceutical Research \& Allied Sciences, 9(3), 143-153.

Kenubih, A., Mammo, B., Terefe, G., \& Fentahun, T. (2021). Assessment of the Impact of Sheep and Goat Pox Lesions on Skin Quality in Selected Ware Houses of Central Ethiopia. Veterinary Medicine: Research and Reports, 12, 199. doi:10.2147/ VMRR.S305705.
Kim, N. Y., Chang, D. S., Hur, G. H., Lee, T. Y., \& Yang, J. M. (2017). Immunogenicity and Protective Efficiency in Mice of a Smallpox DNA Vaccine Candidate.J Bioterror Biodef, 8(155), 2. doi:10.4172/2157-2526.1000155.

Law, M., \& Smith, G. L. (2001). Antibody neutralization of the extracellular enveloped form of vaccinia virus. Virology, 280(1), 132-142.

Lin, C. L., Chung, C. S., Heine, H. G., \& Chang, W. (2000). Vaccinia virus envelope H3L protein binds to cell surface heparan sulfate and is important for intracellular mature virion morphogenesis and virus infection in vitro and in vivo. Journal of Virology, 74(7), 3353-3365.

Matho, M. H., de Val, N., Miller, G. M., Brown, J., Schlossman, A., Meng, X., Crotty, S., Peters, B., Xiang, Y., Hsieh-Wilson, L. C., et al. (2014). Murine anti-vaccinia virus D8 antibodies target different epitopes and differ in their ability to block D8 binding to CS-E. PLoS Pathogens, 10(12), e1004495. doi: 10.1371/journal.ppat.1004495.

Matho, M. H., Maybeno, M., Benhnia, M. R. E. I., Becker, D., Meng, X., Xiang, Y., Crotty, S., Peters, B., \& Zajonc, D. M. (2012). Structural and biochemical characterization of the vaccinia virus envelope protein D8 and its recognition by the antibody LA5. Journal of virology, 86(15), 8050-8058. doi:10.1128/JVI.00836-12.

Melamed, S., Israely, T., \& Paran, N. (2018). Challenges and achievements in prevention and treatment of smallpox. Vaccines, 6(1), $\quad 8 . \quad$ doi:10.3390/vaccines 6010008.

Ramírez, J. C., Tapia, E., \& Esteban, M. (2002). Administration to mice of a monoclonal antibody that neutralizes the intracellular mature virus form of vaccinia virus limits virus replication efficiently under prophylactic and therapeutic conditions. Journal of General Virology, 83(5), 1059-1067.

Rouby, S. R., Safwat, N. M., Hussein, K. H., Abdel-Ra'ouf, A. M., Madkour, B. S., Abdel-Moneim, A. S., \& Hosein, H. I. (2021). Lumpy skin disease outbreaks in Egypt during 2017-2018 among sheeppox vaccinated cattle: Epidemiological, pathological, and molecular findings. PloS one, 16(10), e0258755. doi:10.1371/journal. pone.0258755.

Shchelkunov, S. N., Sergeev, A. A., Yakubitskiy, S. N., Titova, K. A., Pyankov, S. A., Kolosova, I. V., Starostina, E. V., Borgoyakova, M. B., Zadorozhny, A. M., Kisakov, D. N., et al. (2021). Adaptive Immune Response to Vaccinia Virus LIVP Infection of BALB/c Mice and Protection against Lethal Reinfection with Cowpox Virus. Viruses, 13(8), 1631. doi:10.3390/v13081631.

Teffera, M., \& Babiuk, S. (2019). Potential of using capripoxvirus vectored vaccines against arboviruses in sheep, goats, and cattle. Frontiers in Veterinary Science, 6, 450. doi:10.3389/fvets.2019.00450.

Tulman, E. R., Afonso, C. L., Lu, Z., Zsak, L., Sur, J. H., Sandybaev, N. T., Kerembekova, U. Z., Zaitsev, V. L., Kutish, G. F., \& Rock, D. L. (2002). The genomes of sheeppox and goatpox viruses. Journal of Virology, 76(12), 6054-6061.

Tuppurainen, E., Dietze, K., Wolff, J., Bergmann, H., BeltranAlcrudo, D., Fahrion, A., Lamien, C. E., Busch, F., SauterLouis, C., Conraths, F. J., et al. (2021). Vaccines and Vaccination against Lumpy Skin Disease. Vaccines, 9(10), 1136. doi:10.3390/vaccines9101136. 
Vogt, A. C. S., Roesti, E. S., Mohsen, M. O., Leonchiks, A., Vogel, M., \& Bachmann, M. F. (2021). Anti-IAPP Monoclonal Antibody Improves Clinical Symptoms in a Mouse Model of Type 2 Diabetes. Vaccines, 9(11), 1316. doi:10.3390/vaccines9111316. 